\title{
Co-operative agreements and the EU Water Framework Directive in conjunction with the Common Agricultural Policy
}

\author{
I. Heinz \\ Institute of Environmental Research, Technische Universität Dortmund, Germany \\ Received: 16 May 2007 - Published in Hydrol. Earth Syst. Sci. Discuss.: 12 June 2007 \\ Revised: 30 January 2008 - Accepted: 10 March 2008 - Published: 9 May 2008
}

\begin{abstract}
This paper discusses the significance of voluntary arrangements for the water and agricultural policies in the European Union. The current implementation of the European Water Framework Directive (WFD) and the reform of the Common Agricultural Policy (CAP) require new approaches in water management. As many case studies have shown, co-operative agreements (CAs) between water companies, farmers and authorities can help to reduce environmental pressures on water bodies. The main reasons for that are: i) water companies are ready to advise and financially support farmers in changing production methods; ii) changes of farming practices are tailored to the site-specific requirements; iii) farmers and water companies are interested in minimising the costs and environmental pressures as they benefit, for example, from modernization of farming methods, and reductions in cost of water treatment, and iv) voluntarily agreed commitments to change farming practices are often stricter than statutory rules. Moreover, precautionary rather than remedial measures are preferred. Tackling diffuse pollution is one of the main concerns of the WFD. CAs can enhance the cost-effectiveness of actions within the programmes of measures so that good water status is achieved by 2015 . In CAs all relevant stakeholders, located in catchment areas of agricultural usage, can be involved. Thus, they can help to foster integrated water resources management. In particular, disproportionate costs of changing farming practices can be identified. With regard to the recent CAP reform, financial support for farmers will be linked to compliance with environmental standards and further commitments. This concerns both direct payments and agri-environmental programmes. The experience gained in CAs can provide information on best agricultural practices. Informed farmers are more ready to meet environmental requirements. Because
\end{abstract}

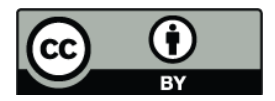

Correspondence to: I. Heinz (iheinz@infu.uni-dortmund.de)
CAs implement the most cost-effective changes in farming practice, it can be assumed that farmers will not face considerable costs due to the new EU water and agricultural policies. Some examples of CAs are described and the significance of CAs in the implementation of the WFD and CAP reform will be highlighted. The article closes with an outlook on the needs of future research activities.

\section{Introduction}

The implementation of the European Water Framework Directive (WFD) and the reform of the Common Agricultural Policy (CAP) require new approaches in environmental policy. The achievement of good status of water bodies by 2015 is one of the main challenges. The key elements of the CAP reform of 2003 and 2004 are: i) "decoupling" direct payments to farmers from production, ii) linking the granting of financial aid to the compliance with environmental standards and further commitments (e.g. food safety and animal health), and iii) support for rural development. In particular, environmental problems related to water and soil could be solved for instance by reducing diffuse pollution, conserving aquatic biotopes, and more efficient utilisation of scarce water resources in irrigated agriculture.

As many studies have shown, voluntary agreements between farmers and other stakeholders can enhance the effectiveness of environmental regulations. Due to the selfinterest of each of the parties involved in such agreements, the costs of changing farming practices can be reduced, so that the achievement of environmental objectives will be assisted. Each of the participants in such agreements is motivated to exchange knowledge and expertise in order to find out those combinations of measures that will improve their situation. For instance, water companies are informed by farmers on their fertiliser and pesticides usage to demonstrate their efforts to reduce or prevent pollution. On the

Published by Copernicus Publications on behalf of the European Geosciences Union. 
other hand, farmers expect compensation payments from water companies and free advisory services. Similarly, water companies advise farmers on conversion to more sustainable farming practices in order to prevent costly remedial measures (such as water treatment, closing wells and conveyance of remote water resources).

The water authorities are interested in promoting such agreements, and they advise both farmers and water companies in their applications for public funding from agrienvironmental programmes. Moreover, the authorities often accept voluntarily-agreed commitments as substitutes for compulsory rules as they recognise that such agreements can make the enforcement of regulations more effective. There are several reasons for that. Due to the collaboration of water companies with farmers, the changes of farming practices can be tailored to the site-specific conditions and environmental problems in water catchments. The monitoring systems installed by water companies are often more advanced than those of the authorities. Moreover, voluntarily-agreed commitments to change farming practices are often more stringent than mandatory rules; this is because water companies are usually more interested in preventing pollution rather than in lessening damages. For instance, as many examples of agreements show, the retention periods for the application of nutrients on farmland are longer and the values for pollutants are often below statutory limits (Heinz et al., 2002a).

Tackling diffuse pollution caused by agriculture is a key concern of the WFD (EU Regulation 2000/60). It can be expected that the cost-effectiveness of actions needed to implement the programmes of measures (Article 11) will be enhanced by voluntary agreements. Moreover, the WFD requires that rising trends in pollution need to be reversed, and further deterioration should be prevented. As mentioned, agreements between farmers and water companies aim to prevent further pollution and avoid the need of any future water treatment or other measures, such as closing wells and conveyance of remote resources. Consequently, agreements promote sustainable water use based on long-term protection of available resources. In some EU Member States such agreements have already been established for more than 20 years. It is assumed that the benefits in terms of reduced loads of nutrients and pesticides in water bodies will become apparent by 2015 .

According to Article 4 (5) of the WFD, the achievement of water-related objectives should be affordable and should not cause disproportionate costs. As voluntary agreements are open to all relevant interest groups, the various cost-benefit impacts resulting from the objectives and measures used to reach them are taken into account. Thus, disproportionate costs of changes in farming practice which only result in insignificant improvements in water status can be avoided.

With regard to the recent reform of the CAP, one of the new requirements is to link financial aid provided to farmers to a better compliance with environmental standards and further commitments concerning public health, animal wel- fare and occupational safety. This requirement concerns both the direct payments (EU Regulation 1782/2003) and subsidy programmes to support for rural development (EU Regulation 1698/2005). The experiences gained in voluntary agreements can provide useful information on best agricultural practices. Good knowledge of the site-specific hydrological and agricultural conditions is indispensable in determining the appropriate local objectives and the most cost-effective measures to achieve them. All these factors can influence the compliance with environmental standards. The more costeffective these measures are, the easier compliance with the rules becomes. Curtailments of direct payments or financial support to farmers can possibly be avoided. In the best case, where voluntary agreements result in full compliance with the required water-related standards, the threat of reduced payments to farmers concerning both EU regulations can become irrelevant. Thus, it can be supposed that farmers located in water catchment areas can minimise their financial burdens due to the CAP reforms, if they convert to good agricultural practice as a result of voluntary agreements.

Further policy measures can help to make voluntary agreements more effective in order to assist the implementation of the WFD and CAP reforms. One of them is financial assistance of such agreements from the revenues of water abstraction charges. By that, small water companies can afford to finance voluntarily-agreed commitments, such as compensation payments to farmers, paying agricultural advisers and monitoring services. Such a funding is already practised in some European Member States. Cases can be found, for instance, in the German Bundesland Lower Saxony. In another Bundesland, North Rhine-Westphalia, such abstraction charges have been recently established: those water companies who have founded voluntary agreements with farmers can compensate their expenditure by the exemption from paying charges.

In the next section, the environmental effectiveness and economic efficiency of voluntary agreements between farmers, water companies and authorities will be demonstrated by representative examples. It should be mentioned that voluntary agreements could also aim to settle conflicts on use of scarce water resources. In such cases - which are not discussed further here - agreements between farmers and other water users can play an important role in regions with water shortage. In the subsequent sections, various policy instruments that can promote voluntary agreements will be pointed out, and the significance of such agreements for the implementation of the WFD and CAP reforms will be highlighted.

\section{Experiences on voluntary agreements with farmers}

The objective of the EU-wide research project "Co-operative Agreements in Agriculture as an Instrument to Improve the Economic Efficiency and Environmental Effectiveness of the European Water Policy" was to investigate the occurrence 
and impacts of co-operative agreements (CA) between water suppliers and farmers (Heinz et al., 2002b; Brouwer et al., 2003; Heinz, 2004). In this project, around 50 case studies across 15 EU Member States were carried out. CAs are defined as voluntary agreements entered into as a result of negotiations between farmers and water companies. Authorities participate either directly or indirectly (Box 1).

In nine out of $15 \mathrm{EU}$ Member States CAs were found (Table 1). However, there was large variation in terms of numbers, objectives, commitments and funding. Whereas only one CA exists in the UK, 435 CAs could be identified in Germany. In France with 70 CAs, advising farmers is the main purpose funded by different financial sources. However, only in some cases are water companies directly involved. The key players are chambers of agriculture, and water agencies. In contrast, in Germany compensations paid directly by water suppliers to farmers, and bilaterally binding agreements, play a central role. In each of both countries, more than 30000 farmers are involved. The agricultural area covered by CAs is about 1.6 Mio ha in France and 0.8 Mio ha in Germany. A remarkable number of CAs - relative to the size of the country - could also be found in The Netherlands (nine cases), involving around 1500 farmers and covering a total of 4000 ha. In the study, the water volumes protected by CAs were also estimated. There are many explanations for this unbalanced occurrence of CAs in the EU, such as different shares of groundwater in water abstraction, the assignment of statutory groundwater protection zones, difficulties in enforcement of compulsory rules, and the willingness of water companies and consumers to pay the costs of encouraging farmers to change their production methods. Particularly in Denmark and Germany, there is a strong preference from public to receive drinking water which needs no "chemical" treatment and which is as pure as possible, going even beyond statutory quality standards. This attitude is a major motivation for water suppliers and authorities to give priority to precautionary measures by controlling pollution at source by changing farming practices.

As the case studies mentioned above showed, CAs provide the opportunity to influence effectively the behaviour of farmers. Because regulatory approaches have difficulty in tackling pollution from non-point sources, both water suppliers and authorities rely increasingly on voluntary agreements. This does not mean that compulsory rules become needless. Special rules are enforced in any case (for instance, ban of hazardous pesticides). Compulsory rules are applied if CAs do not work. Local authorities are often announcing their application to apply pressure on farmers to meet voluntary agreements. Principally, mandatory regulations, such as water acts, serve as legal framework to implement standards or limit values through compulsory and voluntary commitments.

With regard to the environmental effectiveness of CAs, there are important factors to be taken into consideration. For many CAs it can take a long time (sometimes several years
Box 1. Features of co-operative agreements.

- Voluntariness and self-interest of the parties involved

- Self-regulation among the participants

- Involvement of the water suppliers as initiator of negotiations and key provider of financial resources

- Targeted to a specific area (water catchment area; water protection zone)

- Written agreements between at least one water supplier and farmers.

and even decades) until improvements in water quality can be determined due to, for instance, the depth of the aquifer, the type of soil, and the recharge rate. Other influencing factors can be changes in crop patterns and climatic conditions (e.g. rainfall, temperature). In many cases, water-protective production methods introduced as a result of the CA could be used as indicators to assess the environmental effectiveness. Examples for changes in farming practice are intercropping, reduction of fertilisers and pesticides, and conversion to permanent grassland. Reductions of the nitrate content in the soil after harvesting, or of the concentration of the pollutant in the percolating water, could be used as further indicators. When assessing the impacts of CAs other benefits, such as greater biodiversity, more healthy foods, improved image of drinking water and agricultural products, should be also considered.

The economic efficiency of CAs can be assessed by comparing the total expenditure for changing farming practices (including advisory programmes and monitoring services) with the costs saved, such as in water treating or blending, conveying remote resources, using mineral fertilisers and pesticides. A CA is economically efficient if the difference between the total saved costs, which are equivalent with economic benefits, and the total expenditure is positive, i.e. the economic net benefit has a value greater than zero. It can be expected that farmers and water companies have strong incentives to increase the net benefits of CAs as far as possible because both parties can gain (win-win situation). Farmers get compensation payments and save costs by improving their production methods, and water companies save costs of remedial measures. All these information can be collected by questionnaires at water catchment areas (Heinz et al., 200b).

In cases where the CAs were designed significantly to maintain a better water quality than prescribed by statutory standards (e.g. $50 \mathrm{mg} / 1$ nitrate concentration), the economic efficiency can also be assessed; however, the economic benefits cannot be measured in terms of saved costs by water companies (there is no risk that the standards will be reached, so 
Table 1. Occurrence of CAs in the EU Member States (a).

\begin{tabular}{lrrrr}
\hline Country & $\begin{array}{r}\text { Number of } \\
\text { agreements }\end{array}$ & $\begin{array}{r}\text { Farms } \\
\text { involved }\end{array}$ & $\begin{array}{r}\text { Agricultural land } \\
(1000 \mathrm{ha})\end{array}$ & $\begin{array}{r}\text { Water abstraction } \\
\left(\text { million }{ }^{3}\right)\end{array}$ \\
\hline Austria & 4 & 285 & 0.4 & 3.8 \\
Denmark & 3 & 415 & 3 & $<2$ \\
Finland & 1 & 400 & 10 & $<1$ \\
France (b) & 70 & 39200 & 1598 & 2150 \\
Germany & 435 & 33200 & 850 & 1880 \\
Luxembourg & 1 & 12 & 0.2 & $<1$ \\
Netherlands & 9 & 1490 & 4 & 320 \\
Sweden & 3 & 100 & 3.4 & 24 \\
UK & 1 & 10 & 0.9 & 7 \\
TOTAL & 527 & \pm 75000 & \pm 2500 & \pm 4400 \\
\hline
\end{tabular}

(a) Some figures are based on estimates especially in those countries with large numbers of CAs. The reference year is 2002.

(b) Mostly advisory services only.

Source: Brouwer et al. (2003), p. 25.

that no alternatives exist with which the cost of the CA can be compared - such as water treatment cost). Water companies are interested in making agreements with farmers which involve a least-cost combination of measures to change farming practices; this is in order to reduce compensation payments to farmers. In these cases, the assessment of the economic efficiency of CAs can be based on a cost-effectiveness analysis given specific water-related goals to be met by the CAs.

It is noteworthy that in Germany nearly $90 \%$ of the CAs can be identified as cases that aim to reach concentrations below statutory standards - in contrast to $31 \%$ in France and $55 \%$ in the Netherlands (Brouwer et al., 2003). Moreover, it should be emphasised that around $75 \%$ of all CAs established in nine Member States (referred to in Table 1) are targeted to prevent statutory standards being exceeded in the future, or to maintain an even better water quality. The reason for this is that water suppliers usually seek to avoid remedial measures (e.g. water treatment). In the water sector, CAs are seen as an effective instrument to prevent the exceeding of statutory limits, or to reverse the increase in pollution before it can reach a level which would exceed such values (Heinz, 2004).

In the following, a few examples of CAs investigated in the EU research project mentioned above will be described (most of them updated to 2006 figures). A typical case with positive economic net benefits is the drinking water supply of the town "Viersen" in the German Bundesland North RhineWestphalia (Table 2). There are four groundwater catchments, each with a special agreement. The CAs involve in total around 200 farmers, and cover a total agricultural area of around 3000 ha. The main agricultural products are maize, cereals, grass, pig fattening and dairy cattle. The total delivery of the water company is 5.5 million $\mathrm{m}^{3}$ supplying around 80000 people. "Viersen-Süchteln" is one of four catchments. Viersen is a town of about 77000 inhab- itants surrounded by intensively used farmlands. About 25 years ago the water company reacted to the increasing nitrate concentration in groundwater by building deep wells. This measure led to a significant decrease in the average nitrate concentration in drinking water from 80 to $35 \mathrm{mg} / \mathrm{l}$ in the nineties. However, the use of deep groundwater did not prove to be a long-term solution due to hydrological reasons. Although the company purchased farmland near to the water works, the effectiveness of this measure was limited, so that the only solution was to enter into negotiations with farmers. As a result, the nitrate concentration in groundwater has been decreasing continuously, so that the average value of $35 \mathrm{mg} / \mathrm{l}$ in drinking water has been maintained, and the installation of a treatment plant could be avoided. As Table 2 shows, the economic net benefit resulting from the CAs amounts at least to 253000 Euro per year. Consequently, a significant increase in water charges could be prevented. The proportion of the costs of the agreements to the water charge is only $3.5 \%$. A further benefit resulting from this solution is the reversal of increasing pollution of the groundwater in accordance with the preventative principle, by which the natural resource will be protected in contrast to the "end-of-pipe" approach.

Another example is the co-operative agreement "Stevertalsperre" located in the German Bundesland North RhineWestphalia (Table 2). The reason for the establishment (in 1989) of this CA was the pollution of surface waters with pesticides. In order to meet the limit in drinking water of $0.1 \mu \mathrm{g} / \mathrm{l}$, the water company installed treatment facilities, including infiltration by activated carbon, to eliminate the pollutants. The objective of the CA was to achieve area-wide agricultural practices without yield and income losses, and to reduce water treatment costs in the long run. The principal focus of the CA was the provision of advisory services, financed by the water company. However, special financial 
Table 2. Examples of co-operative agreements.

\begin{tabular}{|c|c|c|c|}
\hline & $10^{6} \mathrm{~m}^{3} / \mathrm{a}$ & EUR/a & $\mathrm{EUR} / \mathrm{m}^{3}$ \\
\hline \multicolumn{4}{|l|}{ CA "Viersen" } \\
\hline Groundwater abstraction & 5.5 & & \\
\hline CA expenditure of the water company & & 395000 & 0.07 \\
\hline \multicolumn{4}{|l|}{ Saved costs in water treatment } \\
\hline $50 \%$ treatment & & 648000 & 0.12 \\
\hline $75 \%$ treatment & & 972000 & 0.18 \\
\hline Economic net benefit & & More than 253000 & \\
\hline \multicolumn{4}{|l|}{ CA "Stevertalsperre" } \\
\hline Water abstraction & 100 & & \\
\hline CA expenditure of the water company & & 480000 & 0.005 \\
\hline \multirow[t]{2}{*}{ Saved costs in water treatment } & & 1000000 to & 0.10 to \\
\hline & & 1500000 & 0.15 \\
\hline Economic net benefit & & More than 520000 & \\
\hline
\end{tabular}

\begin{tabular}{lccc}
\hline CA "Holsterhausen/Üfter Mark" & & & \\
Groundwater abstraction & 25 & 420000 & 0.016 \\
CA expenditure of the water company & & & \\
\hline $\begin{array}{l}\text { CA "Munich-Mangfalltal" } \\
\text { Groundwater abstraction }\end{array}$ & 90 & 765000 & 0.008 \\
\hline
\end{tabular}

Source: Heinz (2004)

supports - some in conjunction with state funds - have been provided for particular measures. More than 800 of around 2000 farmers settled in the catchment area, which covers approximately 90000 ha, participate in the CA. The farmland involved covers around 30000 ha which is used mainly for arable farming, with maize and cereals being the dominant

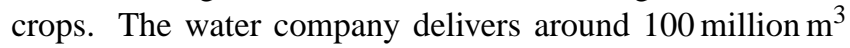
per year, abstracted from the CA region, to about 1.8 million people. The total expenditure of the water supply company for monitoring systems, advisory services, compensation payments and research projects amounts on the average to 480000 Euro per year, or $0.005 \mathrm{Euro} / \mathrm{m}^{3}$.

In the following years the pesticide concentrations decreased slightly, so that the use of activated carbon could be reduced temporarily resulting in cost savings, which varied yearly. For instance, in the period 1989-1999 the use of activated carbon could be reduced from 1200 tons to 200 tons per year. This development was influenced also by the ban of particular pesticides, such as atrazine. Since 2005, no water treatment by activated carbon is needed. This result shows - confirmed by the water supplier - that the voluntary agreements with farmers are successful (Kooperation Landund Wasserwirtschaft, 2007). The economic net benefit resulting from changes in farming practice varies from 0.5 to 1 million Euro per year. The increase of the water costs due to the $\mathrm{CA}$ is about $0.005 \mathrm{Euro} / \mathrm{m}^{3}$, equivalent to a proportion of $0.3 \%$ to the water price. In the future there are uncertainties, in particular, with regard to the application of new pesticides, so that the water company is interested in continuing the $\mathrm{CA}$ to avoid further water treatment and maintain the cost savings. Special water-protective measures, for instance the use of computer-based pesticide sprayers, can be funded from these cost savings. Despite the advantages of the CA, the water authorities are still challenged in controlling effectively the enforcement of mandatory regulations, such as those concerning banned pesticides.

An example established in order to maintain the existing good quality of groundwater is the CA "Holsterhausen/Üfter Mark" in the German Bundesland North Rhine-Westphalia (Table 2). This agreement - one of six CAs between the water company (total water abstraction of around 85 million $\mathrm{m}^{3}$ per year) and farmers - was founded in 1992 and includes about 320 farmers covering around 10000 ha. The average groundwater abstraction in this particular catchment amounts to 25 million $\mathrm{m}^{3}$ per year. The water company financially aids the purchase of modern equipment that results in applications of fertilisers and pesticides targeted to the actual needs of the plants. They include drag hoses, technically-advanced pesticide sprayers, and equipment such as hoes. Further expenditure concerns water-protective measures, such as intercropping, under-seeding, and better applications of semi-liquid manure. All these measures help farmers to comply more effectively with mandatory rules that require the use of environmentally-friendly farming methods. As a result, the concentration of nitrate in drinking water decreased from $13 \mathrm{mg} / \mathrm{l}$ on average to $7 \mathrm{mg} / \mathrm{l}$ (the 
Box 2. Co-operative agreement Fromme Valley - Dorset, Wessex Water, $\mathrm{UK}^{\mathrm{a}}$.

- Operating since 1998

- $19 \mathrm{Ml} / \mathrm{d}$ at risk (total $144 \mathrm{Ml} / \mathrm{d}$ at risk equivalent with approx. one third of the total water supply)

- Significant increase of nitrate concentration

- Water treatment currently applied

- Cost of nitrate removal plant approx. $£ 1.2$ million/year (2000 prices)

- Considerable cost savings could be achieved by the CA if treatment could be partially or entirely abandoned

- Management Plans for farmers financed by the water company

- Catchment management by paying agricultural advisors

- Applying the Catchment Sensitive Farming Scheme (CSF)

- Improved monitoring and modelling

- Financially restrained due to the inability to pass on costs to consumers

${ }^{\mathrm{a}}$ Heinz et al. (2002b)

current mandatory limit value is $50 \mathrm{mg} / \mathrm{l})$. Pesticide loads cannot be detected. The total expenses of the water company amount to about 420000 Euro per year, corresponding to 0.016 Euro $/ \mathrm{m}^{3}$. The proportion to water price is $0.9 \%$. Both the water company and farmers are keen to apply the most effective water-protective methods in order to avoid excessive costs. Thus the goal of this $\mathrm{CA}$ is to achieve a combination of measures that maximises the cost-effectiveness of maintaining good water quality. In this particular case, the CA aims to protect the groundwater resources to a depth of about $100 \mathrm{~m}$ against pollution by pesticides and nitrate. Consequently, the water company can continuously provide customers with high-quality drinking water, with only a negligible increase in water costs.

There are many further examples. In the German Bundesland Hesse, the data of 671 water works were assessed in a recent research project (Bach et al., 2007). By using the regression analysis applied to 11 water works regarding the nitrate pollution of groundwater a trend of decreasing or significant slowing down of nitrate concentration could be proved in 5 cases. In further 3 cases, a decrease of nitrate concentration could be observed. As the authors point out, CAs are definitively a successful instrument for groundwater protection, even though the long time required to determine improvements in water quality currently does not allow to obtain similar results from other cases. Another study to assess systematically the impacts of CAs was carried out in the German Bundesland North Rhine-Westpalia (IWW, 2007).
In this study covering an about 20000 ha agriculturally used area statistically significant influences could be found.

The conversion to organic farming is certainly the biggest change in agricultural practice. In the region of Munich in the German Bundesland Bavaria an example of such a CA can be found. In the CA "Munich-Mangfalltal", founded in 1993, around 100 farmers are involved covering about 2500 ha of agriculturally used land. The water supplier abstracts about 90 million $\mathrm{m}^{3}$ groundwater for more than 1 million inhabitants of the town of Munich (Table 2). Similar to the previous case, the goal of the $\mathrm{CA}$ is to maintain good drinking water quality. At the beginning of 1990 the rising trend concerning the amount of nitrates and pesticides in groundwater continued, although the concentrations were still far below the limit values. Almost $70 \%$ of the farmland within the CA is grassland and no intensive animal breeding exists. The main characteristics of agricultural practice are organic farming (no use of agro-chemicals, upper limit for livestock) and mulch seed in maize cultivation. The water company spends about 765000 Euro per year, or less than 0.01 Euro per $\mathrm{m}^{3}$, for compensation payments and advisory services. The proportion of the water price is $0.7 \%$. Additional payments to farmers are provided from public funds. Since the foundation of the $\mathrm{CA}$, the nitrate concentration in groundwater has decreased from $15 \mathrm{mg} / \mathrm{l}$ to $8 \mathrm{mg} / \mathrm{l}$. The concentration of pesticides declined to the detection limit. In terms of costeffectiveness in maintaining a high-quality drinking water, similar can be said as in the previous case.

As the EU research project on CAs (Heinz et al., 2002b) showed, there are more good examples in other EU Member States that prove the effectiveness of voluntary agreements between farmers, water companies and authorities. In the UK, currently only one case with some elements of CAs - managed by Wessex Water Services Limited (Stanfield, 2006) - could be identified (Box 2). In this country many voluntary measures to tackle the problems of diffuse pollution caused by agriculture have been launched. However, they are based more on governmental agri-environmental programmes rather than on direct negotiations between water companies and farmers in local catchments. An example is the Catchment Sensitive Farming Scheme (CSF). This scheme was introduced in 2005 in response to diffuse pollution impacts on biodiversity. It is mostly focused on reducing phosphate and soil erosion. Catchment officers are employed to educate farmers. Another example is the Environmental Steward Scheme (ESS) of 2005 that aims to enhance biodiversity and where farmers are financially supported (Harris, 2006).

All these initiatives contribute to less pollution in areas of agricultural usage; however, they may be less efficient than CAs where farmers are paid by water companies on the basis of mutual commitment, and on their site-specific expertise concerning the environmental conditions and needs. Both parties are motivated to determine the least-cost and most effective conversion of farming practices and both can win, not 
only in economic terms but also by improving their image in public (for instance, more healthy agricultural products and drinking water). One of the main reasons why CAs are currently not wide-spread in UK is the fact that it is not possible for water companies to pass on costs, such as compensation payments, to consumers through water charges. A further aspect with regard to CAs as instruments to prevent pollution of water resources may be relevant: in contrast to some other EU Member States, such as Denmark and Germany, the readiness of the public and water consumers to pay for going beyond mandatory environmental standards (e.g. for nitrate concentration) seems to be limited. Furthermore, many of the UK regulators have strong reservations against paying polluters not to pollute. They rely more on mandatory rules in order to meet the polluter pays principle (Richardson, 1998).

On the other hand, as the Wessex Water case and many other examples show, water companies must respond to the increasing loads of nutrients and pesticides in waters with costly treatment measures. At the end, the consumers are faced with far higher water prices than needed if the costs of CAs were passed on to them instead. However, the treatment approach has the advantage that the compliance with standards (such as for pesticides in drinking water) can be achieved with a high degree of certainty, whereas the preventative approach by employing CAs is sometimes less certain due to unexpected events in the water catchment area. A further factor of uncertainty is the long lag times between the measures taken and the improvement of the aquatic environment, particularly in areas where immediate action is required to meet statutory drinking water quality, and where the limited availability of water resources does not allow for transitional measures (such as closing wells and water blending). A clear disadvantage of the treatment approach, however, is the fact that it "leaves the problem in the ground" (Stanfield, 2006). Ironically, a few cases in the EU exist where the water companies have to pay twice: simultaneously both to compensate and advise farmers and to treat the pumped water. But these cases are temporary and preferable to the pure treatment approach.

\section{Policies to support voluntary agreements with far- mers}

It is remarkable that in some EU-Member States voluntary agreements between water suppliers and farmers are rare or do not exist at all, even though serious problems caused by agricultural-related water pollution exist. The obstacles for a widespread implementation of this approach in the United Kingdom are mainly institutional. As mentioned, the Government does not permit the passing on of costs of the agreements to the water consumers as part of the water company's operation cost. Apparently in the UK there is a move to change these prohibitive regulations, which would lead to the establishment of more agreements (Harris, 2006). In Italy, the authorities may declare the enforcement of the stricter rules required in the recently- established statutory water protection zones. Because of the advantages of the voluntarilyagreed commitments in terms of economic efficiency, this would trigger negotiations between water suppliers and farmers. Economic incentives and targeted advisory services for farmers would be the key elements of this approach. As long as the implementation of compulsory rules in water protection zones remains difficult, there are good reasons for establishing such agreements. Top-up funding of agreements by using public financial resources may additionally facilitate a more widespread application of the voluntary approach in Italy, especially in those regions where the financial capability of water companies is limited.

As mentioned already, a further policy could be the introduction of water abstraction charges. From the revenue of these charges the costs of agreements can be financed. Such a regulation exists in the Bundesland Lower Saxony in Germany, where the payments of water suppliers both to farmers and to agricultural advisers are reimbursed by the Government from the revenue of water abstraction charges. Thus, even in catchments with small water suppliers and limited financial resources, CAs with farmers can be financed.

Moreover, authorities can promote the establishment of agreements with farmers by giving preference to the outcome of negotiations over compulsory rules (Heinz, 2002). Examples of giving priority for voluntarily-agreed commitments can be found in the German Bundesländer Bavaria, Hesse and North Rhine Westphalia. In these Bundesländer it is possible to complement, or even replace, statutory rules in water protection zones by agreements between water companies and farmers. The rationale for that is the insight that less regulated obligations are more cost-effective as the parties are interested in co-operating to improve their economic situation. In cases where compensation payments have to be provided to farmers by law in water catchment areas with stricter requirements, these payments can be determined more effectively within the framework of CAs, because they are better adapted to the site-specific conditions, and the acceptance by farmers can be reached more easily. This is especially true in cases where farmers get "compensation payments by result", i.e. dependent on the environmental benefits achieved rather than being paid by flat rates, such as for commitments that consider the area of farmland only (e.g. intercropping). An example exists in the CA "Viersen" described above. Formerly granted flat payments related to, for instance, land planting have been replaced recently by a premium which considers the nitrate content in the soil, measured by the $\mathrm{N}_{\min }$ residual value, depending on the type of cultivation. The farmers involved in the CA get, in the case of corn production, 25 Euro per ha if this value is less than $80 \mathrm{~kg} \mathrm{~N} / \mathrm{ha}$, and 50 Euro per ha if this value is less than $60 \mathrm{~kg} \mathrm{~N} / \mathrm{ha}$. Nevertheless, it remains difficult to link payments with improvements in water quality because such improvements resulting from changes in farming practice can take a long time (years, even 
Table 3. Water Framework Directive (WFD).

\begin{tabular}{ll}
\hline Requirements & $\begin{array}{l}\text { Date of } \\
\text { achievement }\end{array}$ \\
\hline Set-up of river basin management plants & 2009 \\
Achievement of cost recovery and incentive water pricing & 2010 \\
Establishment of cost-effective programmes of measures & 2012 \\
Achievement of good status of water bodies & 2015 \\
Justification of derogation from good status of water bodies & 2015 \\
\hline
\end{tabular}

Source: Directive 2000/60/EC of 23 October 2000.

decades). A further problem may be seen in windfall profits for changing production methods that would have been occurred also without financial support. However, as the cases analysed indicate, such windfall profits are probably less than the economic benefits farmers receive from CAs. Water companies make usually great demands on farmers as they aim to prevent or reverse water pollution. Agricultural experts payed by water companies are commissioned to monitor farmers' behavior. In addition, authorities are controlling the compliance with mandatory commitments.

As the EU research project on CAs (Heinz et al., 2002b) showed, the provision of governmental agri-environmental programmes as top funding can promote the establishment of CAs. This is currently practised mostly in those countries where CAs exist. However, if the requirements placed on farmers for receiving financial aid are becoming stricter, the possibilities of top-up funding will be increasingly limited in those cases where the compliance with these requirements is conditional for the granting of such support. Compliance with such requirements is a feature of programmes funded by the EU Commission. A special case of top funding is the CA of Munich-Mangfalltal (Table 2). Here about half of the payments granted to farmers are funded from an agri-environmental programme, as in this catchment area the content of the $\mathrm{CA}$ requires the exclusive practice of organic farming.

A further option to promote CAs in those countries where such agreements are not common, is the establishment of statutory water protection zones together with stricter rules and compensation payments to farmers by law, in particular, if water companies are committed to pay. In those cases, water companies may prefer to pay farmers on the basis of voluntary agreements rather than regulated by compulsory rules. As mentioned already, such agreements are usually more cost-effective. Farmers can also benefit because the conversion of production methods targeted towards the needs of the catchment area can improve their economic position, particularly if the compensation-by-result agreement is being applied.

\section{Co-operative agreements and the implementation of the WFD and CAP reforms}

As the outcome of co-operative agreements between farmers, water companies and authorities in terms of preventing and reducing pollution indicates, the environmental goals in water catchments can be reached more efficiently than by the exclusive enforcement of mandatory rules. As examples in water catchments show, regulatory measures in order to implement the polluter pays principle can promote even remedial measures rather than the protection of water resources. This does not mean that the polluter pays principle is turned on its head. In CAs, farmers usually have to meet statutory rules prescribed in mandatory regulations. Site-specific commitments going beyond these rules are financially supported. There are cases, where advisory services provided by water companies for free are sufficient (Heinz et al, 2002b). Tackling diffuse pollution, in particular that caused by agriculture, is a key concern of the WFD. According to this regulation, rising trends in pollution need to be reversed and further deterioration prevented. Furthermore, measures to achieve a good water status have to be cost-effective and should not result in disproportionate costs (Table 3).

In the following, the reasons why CAs can contribute to the implementation of the WFD are summarised:

1. They aim to prevent increases of pollution, and reverse rising trends. In many cases CAs result in decreases below the permitted limits, (for example, nitrate values fall under $50 \mathrm{mg} / \mathrm{l}$, and pesticides decline to the detection limit). Water companies give preference to precautionary rather than remedial measures (e.g. water treatment). This corresponds with Article 7 (3) WFD.

2. Each of the parties involved have a common interest in determining cost-effective measures to reach sitespecific goals, as required in Article 16(6) WFD. The outcome of CAs can even be identified as win-win-win situations: more efficient farming methods, cost savings in the water sector, and successful enforcement of statutory rules.

3. In determining the site-specific objectives of changing farming practices, the economic benefits are compared with the costs of the measures. By doing that, disproportionate costs in achieving these objectives can be avoided according to Article 4 (5 and 6) WFD. Moreover, certain precautionary and remedial measures can be given priority in order to use limited financial resources as effectively as possible.

4. All relevant interest groups can participate as required in Article 14 WFD. This ensures the exchange of expertise and the articulation of group-specific preferences. Conflicts between water companies, farmers and authorities can be settled in most cases by negotiations. In 
Table 4. EU Regulation 1782/2003.

\begin{tabular}{ll}
\hline Requirements & $\begin{array}{l}\text { Applicable } \\
\text { from }\end{array}$ \\
\hline $\begin{array}{l}\text { Maintenance of farmland in good status } \\
\text { Maintenance of long-term grassland }\end{array}$ & 2005 \\
Compliance with 19 existing EU regulations concerning & 2005 \\
- Nitrate, sludge, groundwater, natural habitats, wild fauna and flora & 2005 \\
- Pesticides, food, animal health & 2006 \\
- Animal protection, etc. & 2007
\end{tabular}

Source: Council Regulation (EC) No 1782/2003 of 29 September 2003 establishing common rules for support schemes under the common agricultural policy and establishing certain support schemes for farmers.

the end, this helps authorities to enforce statutory rules (such as good agricultural practice).

5. The experiences gained through CAs can be applied to watersheds where no water companies are operating. By doing that, area-wide protection of water resources against pollution from agricultural sources can be achieved according to Article 4 WFD.

With regard to the CAP reform, the "decoupling" (i.e. separation) of direct payments to farmers from the volume of production will have positive impacts on water quality (even though several Member States have only partially decoupled certain direct payments). Decoupling direct payments from production volumes can reduce economic incentives for intensive production. Agricultural products that have adverse effects on the aquatic environment can be reduced without losses of direct payments. Nevertheless, changing farming practices can lead to income losses due to increased costs or reduced sales revenues.

Furthermore, the EU Regulation 1782/2003 is playing an important role (Institute for European Environmental Policy, 2005). In particular, this regulation encourages farmers to comply with water-related and other standards concerning public health, food safety, animal welfare and good ecological conditions in order to avoid curtailments of direct payments (Table 4). Moreover, according to the EU Regulation 1698/2005 good agricultural practices prescribed by mandatory rules laid down in environmental laws at national and EU level must be considered by farmers as a condition for being financially assisted. One example is the Nitrates Directive 91/678/EEC. This Directive stipulates the identification of all water affected by nitrate pollution, and prescribes action programmes for the control of nitrate inputs in designated vulnerable zones. It includes compulsory rules for farmers to change their production methods concerning, for instance, the application and storage of semi-liquid manure. Generally speaking, at EU and national level a wide spectrum of water-related regulations exists that contain mandatory commitments for farmers, that are also relevant to the new CAP regulations mentioned. Thus one of the requirements of the WFD, the polluter pays principle, can be fulfilled.

The reasons why CAs can facilitate the implementation of the upcoming CAP reforms include:

1. In many CAs, farmers are committed by contract to meet statutory rules prescribed by regulations at EU, national and local level. As far as the Statutory Management Regulations (SMR) associated with the cross compliance regulation address water-related Directives (such as the Nitrates Directive), this regulation can help to achieve the WFD aims. The same can be applied to the good agricultural and environmental conditions (GAEC) that are defined by the Member States. If farmers involved in CAs do not meet these rules, they can lose the financial aid provided by water companies and complementary public funds. Again, these commitments can ensure that farmers meet the polluter pays principle as they agree to comply with these rules without compensation payments.

2. The cost-effectiveness of CAs plays an important role because this element can contribute towards the limitation of the financial burdens placed on farmers in meeting statutory rules. CAs aim at achieving site-specific objectives in water catchments as cost-effectively as possible. The economic benefits of CAs usually exceed their costs, especially in cases where remedial measures, such as pumping deeper aquifers, water treatment, and development of remote resources, can be avoided. Those cases are appropriate models for achieving good agricultural practices as required, particularly in the EU Regulation 1698/2005 concerning aid for rural development. Here, CAs can help to identify the site-specific environmental needs and the most appropriate measures to meet them. In addition, the specific local agricultural conditions, such as the different productivity and yield prospects, can be taken into account. 
3. Water companies can provide farmers with financial assistance and advisory services in complying with statutory commitments, particularly related to the crosscompliance regulation (EU Regulation 1782/2003), even though this regulation focuses on mandatory commitments and may be less compatible with CAs. Examples of water-protective measures are the maintenance of grassland, set-aside of farmland, and retention periods for spreading semi-liquid manure. However, the obligations agreed upon in CAs often go beyond such commitments, such as prescribed by the Nitrates Directive and the new EU Groundwater Directive of 2007. For instance, the retention periods for applying manure and mineral fertilisers agreed in CAs often exceed compulsory commitments by several weeks and even months, as, for example, in the CA "Viersen" (Table 2) where spreading is not allowed between 1 September and 15 February, in contrast to the statutory rule with a retention period between 1 November and 31 January.

4. CAs are open for further interest groups to participate, such as nature conservation bodies. By that, environmental, ecological and other goals, such as conservation of landscapes, can also be subjects of agreements. Examples of such area-wide and multi-domain agreements in water catchments can be found in the German Bundesland Lower-Saxony (Nolte and Osterburg, 2006). In this Bundesland, the so-called "Gebietskooperationen" have been founded in 28 sub-river basins. For each of these basins a river management plan, including the agricultural sector, will be established (Heddinga, 2006; Newig, 2006).

5. Experience gained in CAs regarding the most appropriate changes in farming practice can be transferred even to regions where CAs do not exist. Depending on the different site-specific conditions, these changes can be used as models for granting payments to farmers according to the EU Regulations 1782/2003 and $1698 / 2005$. For both regulations the compliance with rules of good agricultural practice is conditional. The compliance with the requirements is dependent on the site-specific hydrological, agricultural and socioeconomic conditions. Particularly with regard to the latter regulation, the experiences gained in CAs can help to apply agri-environmental programmes as costeffectively as possible. Examples are the employment of advanced techniques in spreading semi-liquid manure, the switchover of arable to grassland, and the exchange of farmland with different crop patterns (Nolte and Osterburg, 2006). On the other hand, particularly with regard to the cross compliance regulation practical difficulties may emerge as the requirements are defined normally at a central level, while water protection rules aim to tackle regional or local problems.
It is noteworthy that the requirements specified in the WFD can play an important role as commitments for the agricultural sector in performing the CAP reform (Ecologic, 2006). In particular, the reports according to Art. 5 WFD can provide information for setting the objectives relevant for implementing the rural development measures related to water problems. Furthermore, according to the Art. 38 and 39 of Regulation 1698/2005 support shall be granted to farmers for costs incurred and income forgone resulting from disadvantages in the areas related to the implementation of WFD and other relevant EU Directives. Payments cover only those commitments going beyond mandatory requirements. The impacts of the financial supports provided is influenced inter alia by the extent to which the supported measures are tailored to the local conditions and environmental needs. Advisory services for farmers how to apply these measures can also enhance the effectiveness of the supports. In light of the statements made above CAs can contribute directly and indirectly to achieving simultaneously the objectives of the WFD and CAP policies in numerous ways (Box 3) (Heinz et al., 2002a).

\section{Conclusions}

Do "soft" regulations matter? (Just and Heinz, 2000). Are voluntary approaches needed to enforce compulsory rules? The importance of CAs has also been proved for other environmental policies (Carraro and Lévêque, 1999; Hagedorn, 2002). Although there are recent studies on CAs related to water policies (Water4All, 2006; WagriCo, 2007), further research activities are needed. First, the various applications of CAs in Europe and other countries (O'Toole, 1998; Gasteyer, 2003) and their impacts on the aquatic environment should be analysed. Meanwhile, the investigation carried out from 1999 to 2002 (Heinz et al., 2002b) must be updated and extended to the larger European Community (to include the 27 Member States who have joined since then). Do CAs exist in the new Member States and what are their features? How can countries without CAs learn from the Member States with experiences in the field of voluntary approaches to tackle water problems?

The effects of CAs in terms of environmental effectiveness and economic efficiency, and the lessons learned over the past years, should be pointed out in an area-wide comparative analysis. By updating the results from previous investigations, the impacts of CAs on water status with a longterm perspective will be demonstrated. This perspective is needed as it usually takes many years to measure these impacts. Such an analysis could provide new insights on costeffective strategies in protecting water bodies against environmental pressures, and can assist the implementation of the EU water and agricultural policies.

The assessment of the contribution of CAs to reach the WFD objectives should focus on issues such as: more 
efficient use of scarce water resources in irrigated agriculture, reduction of pollution from diffuse sources, enforcement of the polluter pays principle, and achievement of good water status. In addition, a better knowledge of the role of CAs in the process of implementing the CAP reform in conjunction with water policy is needed. The role of CAs in achieving the objectives of the CAP reform, including the support for rural development, cross-compliance regulation and de-coupling policies, is to be analysed in greater detail.

Furthermore, the advantages of area-wide CAs covering entire watersheds should be pointed out. In contrast to CAs located in contained water catchment areas, basinwide agreements between stakeholders will become increasingly important for the establishment of river basin management plans as regulated in the WFD. In particular, CAs can help to settle conflicts between farmers, water companies and other stakeholders in developing cost-effective programmes of measures. Typical examples for such integrated water management on a voluntary basis can be found in the German Bundesländer Lower Saxony (Heddinga, 2006) and Schleswig-Holstein (Grett, 2007). As the latter example shows, in particular, the stakeholders involved (including farmers) could found an agreement on measures that must be postponed until after the WFD deadline 2015, otherwise disproportionate costs would emerge.

The role of area-wide CAs in synchronising the implementation of the WFD and CAP reform should be analysed in greater detail. For instance, the programme of measures to be established in river basins according to Article 11 of the WFD can impose restrictions in land use, such as more extensive farming or set-aside of agricultural land. Some of those restrictions are also required by CAP regulations in the particular areas. In such cases, experiences gained with CAs may provide advice on how to find an agreement with farmers by negotiation. With respect to possible curtailments of direct payments or financial assistance to farmers, CAs may help to find agreements among the stakeholders in water catchment areas, and cases can be identified where exemptions are to be made due to disproportionate costs according to Art. 4 (5) WFD. By specifying more precisely the local commitments based on the rules of good farming practice and finding out the most cost-effective measures to meet them, the enforcement of the polluter pays principle as required by the WFD can be assisted. CAs employ monitoring equipment that is often more effective than the control systems used by authorities. Furthermore, CAs can help to distinguish the additional needs and requirements as regulated in the WFD, from the rules of good agricultural practice. The provision of such site-specific information will assist the authorities in granting agri-environmental programmes to farmers by tuning those commitments to the local conditions, that go beyond the compulsory rules.

Training programmes to improve and implement CAs are to be developed in regions where fewer experiences on voluntary arrangements could be gained. Last but not least, fac-
Box 3. Co-operative agreements support WFD and CAP.

- Prevent increase of pollution

- Reverse rising trends of pollution

- Determine cost-effective measures to achieve water-related and other objectives

- Contribute to the implementation of the polluter pays principle

- Avoid disproportionate costs

- Incorporate stakeholders

- Advise farmers on complying with environmental and other standards

- Keep financial burdens of farmers and water consumers moderate

- Improve the effectiveness of agri-environmental programmes in watersheds

- Assist integrative water management by area-wide and multi-domain agreements

tors hampering the successful implementation of CAs, especially in countries where such agreements hardly exist, should be analysed and appropriate strategies on how to remove barriers are to be examined. Factors hampering the wide-spread application of CAs include the preference of some water companies for installing treatment plants in order to ensure the compliance with statutory quality standards, high demands of farmers for compensation payments (especially in case of intensive livestock farming), and the long time delay between establishing a CA and meeting regulatory standards. In addition, special regulations can impede the creation of CAs, such as the inability of water companies to pass on the costs to the consumers, as previously mentioned.

However, as the experience gained in some EU Member States indicates, the effectiveness of the EU water and agricultural policies, both strongly interrelated, can be improved by voluntary approaches. The lessons learned in these States should be transferred to those countries where CAs are not common and where the command-and-control measures prevail.

Edited by: S. Barles 


\section{References}

Bach, M., Hoch, A. S., Friedrich, S., Frede, H.-G., und Berthold, G.: Wirksamkeit und Kosten von Kooperationen zur grundwasserschonenden Landbewirtschaftung in Hessen, Wasser Abwasser, 148(5), 358-363, 2007.

Brouwer, F., Heinz, I., and Zabel, T. (Eds.): Governance of Water-related Conflicts in Agriculture - New Directions in Agrienvironmental and Water Policies in the EU, Kluwer Academic Publishers, Dodrecht/Boston/London, 2003.

Carraro, C. and Lévêque, F. (Eds.): Voluntary Approaches in Environmental Policy, Dodrecht, Boston, London, 1999.

Ecologic: CAP \& WFD. Water Framework Directive meets Common Agricultural Policy - Opportunities for the Future. Research Project, funded by the EU Commission, Contract no. SSPE-CT2005-006618-CAP-WFD, 2006.

Fohrmann, R.: Entwicklung eines einheitlichen Verfahrens zur Erfassung und Bewertung der Auswirkungen von Vereinbarungen zwischen Landwirtschaft und Wasserwirtschaft auf die Gewässerqualität in Nordrhein-Westfalen, Mülheim an der Ruhr, IWW Journal, 27, 10-11, 2007.

Gasteyer, S.: Water utility - farmer co-operation in the US, in: Governance of Water-related Conflicts in Agriculture - New Directions in Agri-environmental and Water Policies in the EU edited by: Brouwer, F., Heinz, I., and Zabel, T., Kluwer Academic Publishers, Dodrecht/Boston/London, 181-205, 2003.

Grett, H.-D.: Bewirtschaftungsplanung in Schleswig-Holstein, Workshop Maßnahmenauswahl und Kosteneffizienzanalyse nach EU-Wasserrahmenrichtlinie, Zentrum für Umweltforschung (UFZ), Leipzig, 13-14 February, http://www.ufz.de/index.php? de $=10883$, last access: 28 April 2008, 2007.

Hagedorn, K. (Ed.): Environmental Co-operation and Institutional Change. New Horizons in Environmental Economics, Edward Elgar, Cheltenham (UK), Northampton, MA (USA), 2002.

Harris, B.: A perspective on UK initiatives relating to WagriCo. Kick-off workshop of the project "Water Resources Management in Co-operation with Agriculture (WAgriCo)", Hannover, 9-10 March, http: //www.wagrico.de/, http://www.nlwkn.niedersachsen.de/master/ C19945433_N19944660_L20_D0_I5231158.html/, last access: 28 April 2008, 2006.

Heddinga, B.: Gebietskooperationen - der niedersächsische Weg zur Umsetzung der EG-Wasserrahmenrichtlinie, Präsentation auf dem 11. Grundwasserworkshop, 11 October 2006, Hildesheim, 2006.

Heinz, I.: Co-operative agreements to improve efficiency and effectiveness of policy targets, Nature and Agriculture in the European Union. Current Issues in Ecological Economics, edited by: Brouwer F. and v. der Straaten, J., Edward Elgar, Cheltenham, UK, Northampton, USA, 233-251, 2002.

Heinz, I., Andrews, K., Brouwer, F., and Zabel, T.: Voluntary arrangements to cope diffuse pollution from agriculture and their role in European water policy, Water Sci. Technol., 46(6-7), 27$34,2002 \mathrm{a}$.
Heinz, I., Brouwer, F., Andrews, K. and Zabel, T.: Co-operative Agreements in Agriculture as an Instrument to Improve the Economic Efficiency and Environmental Effectiveness of the European Water Policy, Research Project, funded by the EUCommission, Contract no. ENV4-CT98-0782, 2002b.

Heinz, I.: Kooperation zwischen Wasserversorgungsunternehmen und Landwirten - Eine EU-weite Analyse, GWF Wasser Abwasser, 145(4), 263-267, 2004.

Institute for European Environmental Policy: http://www.ieep.eu/ projectminisites/crosscompliancenetworkproj/index.php, last access: 28 April 2008, 2005.

Just, F. and Heinz, I.: Do "soft" Regulations matter?, in: CAP Regimes and the European Countryside, edited by: Brouwer, F. and Lowe, P., CABI Publishing, Wallingford, Oxon (UK), New York (USA), 241-255, 2000.

Kooperation Land- und Wasserwirtschaft im Einzugsgebiet der Stevertalsperre (Hrsg.): Bericht über die Ergebnisse der Beratung in 2006, Coesfeld, 2007.

Newig, J.: Institutionelle Herausforderungen bei der Umsetzung der Wasserrahmenrichtlinie am Beispiel der Gebietskooperationen in Niedersachsen, Präsentation auf dem 11. Grundwasserworkshop, 11 October 2006, Hildesheim, 2006.

Nolte, L. and Osterburg, B.: Beiträge ländlicher Entwicklungsprogramme zur Reduzierung diffuser Gewässerbelastungen aus der Landwirtschaft am Beispiel Niedersachsen, Wasser und Abfall, 7/8, 16-22, 2006.

O'Toole, L. J.: Control Capacity - United States, in: Drinking Water Supply and Agricultural Pollution. Preventive Action by the Water Supply Sector in the European Union and the United States, edited by: Schrama, G. J., Kluwer Academic Publishers, Dordrecht, Boston, London, 341-364, 1998.

Richardson, J. J.: Policy Framework - England and Wales, Drinking Water Supply and Agricultural Pollution. Preventive Action by the Water Supply Sector in the European Union and the United States, edited by: Schrama, G. J., Kluwer Academic Publishers, Dordrecht, Boston, London, 231-251, 1998.

Stanfield, P.: The project WAgriCo an opportunity to improve the quality of drinking water. Kick-off workshop of the project "Water Resources Management in Co-operation with Agriculture (WAgriCo)", Hannover, 9-10 March, http: //www.wagrico.de, http://www.nlwkn.niedersachsen.de/master/ C19945433_N19944660_L20_D0_I5231158.html, last access: 28 April 2008, 2006.

Water4All: Sustainable Groundwater Management, Research project, sponsored by the European Commission and Interreg North Sea Region, http://www.water4all.com, last access: 28 April 2008, 2006.

WagriCo: Water Resources Management in Cooperation with Agriculture, Research Project, funded by the European Commission, http://www.nlwkn.niedersachsen.de/master/ C19945433_N19944660_L20_D0_I5231158.html/, http: //www.wagrico.org/site/WAgriCo/content-folder/holding-page/, last access: 28 April 2008, 2007. 